\begin{tabular}{lllll}
\hline Volume 70 & Number 3 & Sptember 2006 & Barcelona (Spain) & ISSN: 0214-8358 \\
\hline
\end{tabular}

\title{
Editorial
}

\section{INFORMATION, COMMENTS AND THOUGHTS ON EDITING SCIENTIA MARINA}

\author{
Pere Abelló \\ Outgoing Editor-in-Chief
}

Dear friends and colleagues,

This is just to let you know that my role as Editor-in-Chief of Scientia Marina finished last May. Dr. Maria Pilar Olivar has now taken over as the new Editor-in-Chief of our journal.

I am very proud to have accepted the responsibility of leading our journal during the last four and a half years. It has been a difficult period in which we have managed to improve many aspects of the journal and started to adapt it to the new internet media technologies. All these achievements would not have been possible without a good team. I am therefore very grateful to all those who have helped to run and improve the journal in many areas. First of all, without the assistance of the Secretariat and Assistant Editors, no journal can ever be published. The Technical Staff also form an essential part of the journal. In addition, all the work carried out by the Scientific Editors, the referees and, of course, the authors undoubtedly form the core of the end product.

Together we have managed to slowly introduce changes aimed at improving the journal and adapting it to the new technologies. The first change that we fully introduced was (it now seems so obvious!) the implementation of the revision process of manuscripts through electronic mail. This step certainly speeded up the revision process, or at least this was the intention, because, as we all know, not just the Scientific Editors but also most of the referees are very busy, and the revision of manuscripts is not always the first priority that we researchers put on our list. Too often the revision of manuscripts is delayed, especially when manuscripts are not perfect in either the science, the format or the language used.

We have managed not only to keep our place within the Science Citation Index Impact Factor but to almost double its value in the last year: the 2005 evaluation provided an Impact Factor of 1.036 ! We are not (yet) one of the top journals in our field, but we certainly are a good journal. We have maintained our position and wish to continue improving.

The number of manuscripts that we have received has been increasing year by year, and this has led us to build up an adaptive mechanism within our way of running the journal. When I took up my role as Director/Editor-in-Chief of the journal in 2002, we had been processing a total of 94 manuscripts the year before. The number of manuscripts received by our journal has been increasing at an annual rate of $17-21 \%$, and in 2005 it reached the figure of 159 . This has prompted the addition of new members to the Editorial Board (the Scientific Editors) according to the subject of the new manuscripts in order to avoid assigning too many manuscripts to the same Scientific Editors and overloading them with work. The frequency of the meetings of the Editorial Committee, as well as its composition, have, of course, also changed accordingly.

One of the most important changes that we have introduced is to provide open access to the published papers through the web. As all of you now know, all published articles can now be freely read and downloaded from our web site. This has certainly opened and increased the dissemination of our journal and we wish to believe that in this way the product of the research of our authors will be more widely distributed.

We have also started to upload the older issues of the journal on the website. This is one of the subjects that the new editorial team is going to deal with in the following mandate.

It should be borne in mind that Scientia Marina is an institutional journal: it is the journal of the Institut de Ciències del Mar (CSIC) in Barcelona. All editing printing and distribution costs 
have so far been met by the Institute, so all subjects studied by the Institute should form the core of the journal. It is an international and interdisciplinary journal open to most subjects within marine sciences, and when a journal is open to many (too many?) subjects, it is ultimately shaped by its authors. It depends on the manuscripts that it receives, and the end product is a reflection of the proportion of manuscripts sent for each subject. This makes us what we are: an interdisciplinary journal based mainly on biological oceanography (in its broadest sense, ranging from microbiology and phytoplankton to fisheries and general marine ecology). The proportion of manuscripts (and articles) on physical oceanography is much lower, and that of contributions on marine geology and chemistry is even lower. According to the geographical areas studied in the submitted and published manuscripts, our journal also has a main geographical focus: the Mediterranean Sea and the adjacent Atlantic Ocean. However, it also includes important contributions from the Antarctic Ocean and from Latin American countries.

One aspect that has constantly worried me during these last few years is the failure of many authors to follow the rules requested by the journal. I understand that a manuscript may have some errors in its format - we are all human - but too often the authors do not follow our journal's style, especially with regard to references. Too often also the format of manuscripts follows that of other journals, curiously enough ones with a higher impact factor, meaning that the authors have not even bothered to "waste" their time adapting the format of their article for their new submission. Of course, in these cases, they are certainly wasting their time. I personally cannot understand it. If you want to publish in a journal, you have to follow its rules, whether you like them or not. I may understand the point of view that the most important aspect is the science in the article, not the format, but I am personally not willing to waste my time doing what the authors should have done. The publishing of a journal is a collective task and we all gain if everyone does their job properly.

Overall, the experience of running this journal has been a good, and highly rewarding one. I think that it is very positive for a scientist, for an author, to be on the other side, the editor-publisher's side. One learns a lot, not only about the right things to do, but also-and perhaps most importantly-about the things not to do.

As an editor, one makes friends by accepting a manuscript, and sometimes 'enemies' by rejecting one. One never has a good feeling when rejecting a manuscript (our present rejection rate is around 55\%), but the quality of the journal must always be maintained and improved, and the number of pages to be published per year is finite, so a selection is needed. Our system for assessing manuscripts - the Scientific Editor assigned to a manuscript by the Editorial Committee makes a recommendation to the Editor-in-Chief on whether to accept or reject a manuscript based on the reports of the reviewers freely chosen by him/her and on his/her own report-has both advantages and drawbacks, but it has been very useful to us for many years. We have always tried to keep away from pressures by the authors for a manuscript to be published-yes, this sometimes happens and it is usually not good for the final result. A really good manuscript does not need a phone call or additional message for it to be accepted. The editor of a journal needs to take care of the quality of the journal and is free to choose the advisers needed, whoever they are and whatever nationality they are, and regardless of the personal need of an author to place one more published paper in his/her $\mathrm{CV}$ as soon as possible. We have to act professionally, and a scientific manuscript has to be accepted for the science in it (always following the requested format, of course!), not for the prestige of the authors or their personals needs.

These are some of my personal thoughts and feelings that I wanted to share with you. I feel very proud of having directed the journal during the last four years. It has been a very fruitful experience. I wish my successor, Dr. Maria Pilar Olivar, the best of luck, and I also offer her all my experience and collaboration. I am very aware that the running of a journal is not just the result of the editor's work, but depends on the whole team.

Thank you to all of you who have in some way or another helped us to attain the present level of quality, and please forgive me if this editorial letter has ended up being too long. 